\title{
GERENCIAMENTO DE RESÍDUOS SÓLIDOS: \\ DESTINAÇÃO E RECICLAGEM
}

Pedro Henrique Santos Bisi ${ }^{1}$

Pedro Fernando Cataneo ${ }^{2}$

Fernando Ferrari Putti ${ }^{3}$

RESUMO: O presente trabalho apresenta um estudo de levantamento e compilação bibliográfica sobre o gerenciamento de resíduos sólidos, suas devidas destinações e possível abrangência econômica, através da reciclagem, tentando exercer uma sustentabilidade urbana com reutilização de materiais antes indevidamente descartados, devido a lei posta em vigor em agosto de 2012, provendo o correto gerenciamento para que não haja impactos ambientais.

Palavras-chave: Resíduos sólidos, reciclagem, gerenciamento.

\section{INTRODUÇÃO}

Podemos nos basear na produção de resíduos sólidos, tendo como referência inicial, a evolução do homem, quando o mesmo deixou de ser nômade, e iniciou a fixação de suas moradias, transformando assim a região ambiental, para produção de suas lavouras e criação de animais, iniciando o desenvolvimento de novas tecnologias.

\footnotetext{
${ }_{1}^{1}$ Aluno do Curso de Administração, CET UNESP/Tupã. phbisi@hotmail.com.

${ }^{2}$ Professor Doutor, UNESP/Tupã. pedro@tupa.unesp.br.

${ }^{3}$ Mestrando em Agronomia (Irrigação e drenagem) FCA UNESP/Botucatu. fernandoputti@fca.unesp.br
} 
Com o inicio da Revolução Industrial (século XIX), a aglomeração de pessoas em um determinado espaço geográfico, levou com que as cidades se tornassem ambientes degradados. Somando-se a este fato, o êxodo rural, que fez com que ocorresse o aumento exacerbado e descontrolado dessas cidades.

Juntamente com o aumento das cidades, obteve-se o crescimento de resíduos sólidos, provenientes desde construções civis a dejetos orgânicos, e estes nem sempre tem como destinatário final o local devidamente apropriado. Podendo levar a causar impactos ambientais.

\section{DESENVOLVIMENTO}

\section{RESÍDUOS SÓLIDOS}

Em cima desta produção de resíduos e sua destinação por muitas vezes inapropriadas, foi aprovado à lei no 12305/2010 "POLÍTICA NACIONAL DE RESIDUOS SÓLIDOS - ESTABELECE DIRETRIZES PARA A GESTÃO DOS RESÍDUOS SÓLIDOS”. Entrou em vigor no dia 02 de agosto de 2012, sendo obrigatório para as empresas e administração Pública.

Segundo Bisi:

"A lei dispõe sobre seus princípios, objetivos e instrumentos, bem como sobre as diretrizes relativas á gestão integrada $e$ ao gerenciamento de resíduos sólidos, incluídos os perigosos, ás responsabilidades dos geradores e do poder públicos e aos instrumentos econômicos aplicáveis." (ALMADA BISI, D. Plano de gerenciamento dos resíduos sólidos. Ribeirão Preto: Moraes Cursos, 2012. 31)

RESÍDUOS SÓLIDOS - DEFINIÇÃO 
Constituem-se como resíduos sólidos materiais no qual nós genericamente chamamos de "lixo", são aqueles materiais no qual a sociedade produz e não se faz necessário sua "obtenção", tratando-os como supérfluos ou até mesmo perigosos, dependendo de sua natureza, tendo como melhor apropriação o descarte dos mesmos.

\section{RESÍDUOS SÓLIDOS - ORIGEM}

Podemos classificar vários pontos de origem de resíduos sólidos, entre eles alguns focos de origem temos como principais os resíduos sólidos urbanos, resíduos sólidos domésticos, resíduos domiciliares, resíduos de serviços de saúde, resíduos industriais, resíduos agrícolas, resíduos especiais, entre outros.

Os resíduos sólidos urbanos, podemos citar os resíduos domiciliares, comerciais, institucionais, serviços municipais, e resíduos industriais, etc.

Resíduos domiciliares podemos citar como sendo aqueles provenientes de residências ( casas e apartamentos), desde roupas velhas que depositam nos lixos, até os lixos orgânicos.

No caso dos resíduos comerciais podemos citar como sendo aqueles provenientes de lojas, restaurantes, mercados e supermercados, escritórios, hotéis, etc.

Institucionais originados em escolas, faculdades, etc.

No caso dos resíduos de serviços municipais podemos citar sendo aqueles da poda e manutenção de jardins e praças públicas, área de recreação e varrição de ruas, etc.

E resíduos industriais sendo aqueles provenientes das industrias, mas advindo dos setores administrativos e de refeitórios.

Como resíduos sólidos domésticos podemos classificar como sendo os resíduos sólidos urbanos anteriormente citados mais, entulhos obtidos através da construção civil. Serviços de saúde onde podemos adicionar também ambulatórios, laboratórios, farmácias, núcleos de saúde, etc. Também incluso em resíduos domésticos os resíduos industriais, originados nos processos industriais dentro da região urbana, e classificados como perigosos ou não. 
Como resíduos agrícolas têm aqueles que são advindos das atividades agropastoris que são pertencentes a um grupo de resíduos que podemos denominar como agrícolas, inclusive das provenientes das agroindústrias.

Neste segmento provem aquele tido como perigosos, como embalagens de defensivos agrícolas, adubos e produtos quando vencidos, entre outros.

Resíduos especiais são aqueles provenientes em aeroportos e portos que são tidos de viagens internacionais estes seguem normas de destinação especifica.

\section{DESTINAÇÃO DOS RESÍDUOS SÓLIDOS}

Abordaremos agora os quesitos relacionados a destinação destes resíduos. Estes que por muitas vezes tem como destinações finais locais inadequados, onde podem levar desde a causar impactos ambientais, a deixar de aproveitar seus recursos econômicos.

Como exemplo podemos citar o município de Tupã/SP, onde os mesmo e referência no quesito reciclagem resultado do trabalho das secretarias da cidade especialmente da secretaria do meio ambiente. Onde a cidade já recebeu alguns prêmios pela excelência no trabalho. Porem nem sempre foi assim.

Antes eles não tinham aterro adequado para resíduos domésticos como visto anteriormente, e muito menos para resíduos sólidos provenientes das construções civis, onde estes eram depositados em vicinais e em áreas rurais inadequadas, causam assim impactos ambientais das respectivas regiões e no caso das vicinais, transformando o mesmo em uma trajetória com certo perigo.

Porém este "visual" recebeu mudanças, hoje Tupã tem um dos aterros mais apropriados para dejetos domésticos especificamente orgânicos, onde este escorre o "chorume" para o local certo, e tendo este aterro uma manta entre o aterro e a terra para evitar impactos ambientais.

No caso dos resíduos provenientes das construções civis, há cidade já havia a central de trituramento destes entulhos porem faltava a licença, esta obtida este ano pela CETESBE autorizando assim a operação da usina de tratamento de resíduo sólidos. Com a licença de operação da usina de reciclagem e de entulhos, com isto a prefeitura fez uma reunião com as empresas de caçambas do município de forma a fazer uma triagem para 
que os mesmos levem os entulhos para serem triturados, podendo ser encaminhados para a usina de reciclagem de entulho.

A usina de reciclagem ficou responsável pela logística da operação que será realizada pela própria usina, fazendo reunião com as empresas de caçamba de forma a alinhar os procedimentos a serem adotados para que esses materiais sejam encaminhados para a usina de entulho, para serem triturados e terem sua destinação correta.

Estes resíduos da construção civil quando não reutilizados na construção civil, serão levados triturados a estradas rurais de forma a melhorar a trafegabilidade das pessoas que residem nestas localidades, e quando tiverem que ser despejados os mesmo serão levados para o aterro no córrego Rebolsas onde o mesmo teve uma construção para tal desempenho de forma a não agredir o meio ambiente.

\section{RECICLAGEM COM ENFOQUE ECONÔMICO}

Muito desses materiais produzidos pela sociedade, pode ser reciclado, desde que estes resíduos sejam devidamente tratados. Com isto temos uma forma de oferecer empregos à sociedade e uma renda para os mesmos reduzindo assim com a reciclagem demanda de matérias-primas e energia.

Abordando a questão da reutilização de resíduos sólidos, poderíamos nos aprofundar em vários quesitos, como exemplo usinas de reciclagem de resíduos da construção civil, triturando os resíduos e fazendo tijolos a partir desse material triturado, entre outros vários exemplos.

Porém novamente podemos destacar a prefeitura de Tupã no qual estimula a reciclagem dos resíduos domiciliares, a prefeitura passa um caminhão de tempos em tempos na semana recolhendo o material de reciclagem, papeis, papelão, latas de alumínio, plástico etc., e leva para a cooperativa de reciclagem.

Desta maneira amortizando os impactos que estes materiais fariam caso fossem descartados. Pois com a reciclagem diminui a quantidade de arvores cortada para a produção de papéis, latas de alumínio, embalagens plásticas entre outras. 
Apenas salientando que alguns destes dejetos demoram até séculos para se decompor. Tendo assim varias vantagens decorrentes da reciclagem, como a minimização da utilização de fontes naturais, por muitas vezes essas fontes não são renováveis, e diminuindo assim a quantidade de resíduo que necessita de tratamento no final, e diminuindo os dejetos recolocados nos aterros ou incineração

Um enfoque que não podemos deixar de levar em consideração são os impactos causados por uma empresa de reciclagem ou cooperativa. Já que as mesmas além de retirarem resíduos dos municípios, resíduos estes que seriam por muitas vezes despejados em locais inadequados, podendo causar danos ambientais, gera também fontes de renda para cooperados.

Levando em consideração uma cooperativa de reciclagem, permite com que os cooperados que antes trabalhavam individualmente, e de forma desumana, por passarem horas andando com seus carrinhos pela cidade a recolherem materiais de reciclagem tal como latinhas de alumínio, plástico e principalmente papelão. Chegando ao final do dia e Ihes rendendo em um dia bom de míseros 2 a 5 reais para o sustento da família.

Esta que por sua vez, tem vive em condições precárias, geralmente vivendo em "casebres" de madeira com fiação perigosa devido ao "gato" tido do poste, e a falta de esgoto. Famílias no qual as crianças por muitas vezes a única refeição que terá no dia é aquela que recebe na escola.

Quando estes catadores se juntam a alguma cooperativa de reciclagem, se tornando cooperados, por não se tratar de uma empresa privada, há uma mudança sócioeconômica.

Esses catadores se organizam de forma que há aqueles que trabalham na cooperativa na separação adequada e compactação dos materiais recolhidos e há aqueles que continuam recolhendo o material, o que muda e que ambos os ofícios empregados Ihes geram uma fonte de renda maior, e lhes proporcionam muitas vezes devido a ajudas municipais cursar algum curso técnico que sendo de artesanato para mulheres para uma renda extra, até mesmo escola para terminarem os estudos.

\section{CONCLUSÃO}




\section{Then

Conclui-se, portanto, que há uma mudança na vida dessas pessoas devido a este cooperativismo, mesmo que para muitos sejam algo desprezível, para eles que chegam a triplicar seus ganhos é algo imensurável, já que Ihes possibilita uma condição melhor de vida.

Outro tipo de empresa voltada para a reciclagem que abate dejetos orgânicos e proporcionam vagas de empregos, são empresas de compostagem, que tratam de resíduos que antes eram simplesmente jogados em aterros de forma transformar estes resíduos orgânicos em adubos e fertilizantes.

Esses foram alguns exemplos de diretrizes que se pode tomar a respeito da reciclagem de resíduos sólidos independente da sua composição, sendo orgânicos ou resíduos da construção civil.

Provando-se, desta forma, que materiais antes descartados de forma irregular por muitas vezes, venham a gerar novos empregos e fontes de renda paralelas. Sem considerar os impactos que deixamos de acrescentar ao meio ambiente com a reciclagem.

\section{REFERENCIAL}

ALMADA BISI, D. Plano de gerenciamento dos resíduos sólidos.1 ed. Ribeirão Preto: Moraes Cursos, 2012, 31p.

Boletim Técnico da Escola Politécnica da USP Departamento de Engenharia de Construção Civil: IMPACTOS AMBIENTAIS CAUSADOS POR RESÍDUOS URBANOS: O CASO DE MARINGÁ/PR. Disponível em: $<$ http://publicacoes.pcc.usp.br/PDF/BTs Petreche/BT255\%20Angelis\%20Neto.PDF>. Acesso em: 12 mai. 2012.

CEASA-Curitiba: Plano de Gerenciamento de Resíduos Sólidos. Disponível em: $<$ http://www.ceasa.pr.gov.br/arquivos/File/PGRS CEASA 2010.pdf>. Acesso em: 20 abr. 2012.

Consultoria Legislativa: DESTINO DOS RESÍDUOS SÓLIDOS E LEGISLAÇÃO SOBRE O TEMA. Disponível em:<http://www.mp.ba.gov.br/atuacao/ceama/material/doutrinas/residuos/destino dos re siduos solidos e legislacao sobre o tema.pdf >. Acesso em 26 mar. 2012. 
FIESP: RESÍDUOS SÓLIDOS. Disponível em:<http://www.fiesp.com.br/ambiente/area tematicas/residuos.aspx>. Acesso em: 17 mai. 2012.

Planejamento e Gestão de Resíduos: CARACTERIZAÇÃo DE RESÍDUOS SÓLIDOS. Disponível em:<http://wwwp.feb.unesp.br/joha/Carac_Res_Sol_Fol.pdf>. Acesso em: 15 abr. 2012.

Resíduos sólidos urbanos: COLETA E DESTINO FINAL. Disponível em: $<$ http://pt.shvoong.com/exact-sciences/biology/794227-res\%C3\%ADduoss\%C3\%B3lidos-urbanos-coleta-destino/>. Acesso em: 28 mar. 2012

Silva; J. F. P. :Reciclagem de resíduos sólidos. Disponível em:< http://br.monografias.com/trabalhos2/reciclagem-residuos/reciclagem-residuos.shtml>. Acesso em: 22 mar. 2012.

Wikipédia, a enciclopédia livre: Resíduo Sólidos: Disponível em : <http://pt.wikipedia.org/wiki/Res\%C3\%ADduo_s\%C3\%B3lido>.Acesso em : 26 abr. 2012 